\title{
Daidzein and genestein contents in tempeh and selected soy products.
}

\begin{abstract}
The total isoflavones in tempeh and selected local soy products was determined. Raw tempeh contained $26 \pm 6 \mathrm{mg}$ daidzein $(\mathrm{Da})$ and $28 \pm 11 \mathrm{mg}$ genestein $(\mathrm{Ge})$ while fried tempeh contained $35 \pm 11 \mathrm{mg}$ Da and $31 \pm 11 \mathrm{mg}$ Ge in $100 \mathrm{~g}$ (wet basis). Total isoflavone content in $100 \mathrm{~g}$ of raw tempeh, based on a dry weight, was $205 \pm 56 \mathrm{mg}$ and significantly reduced to $113 \pm 41 \mathrm{mg}$ in $100 \mathrm{~g}$ of fried tempeh. Tempeh in batter was deep-fried for $30 \mathrm{~min}$ which reduced $45 \%$ of the total isoflavone content compared to the raw one. Raw tempeh contained the highest total content of isoflavone among the studied local soy products. Total isoflavone content in processed soy foods like egg tofu and home made soybean drink were significantly lower than other soy products studied.
\end{abstract}

Keyword: Tempeh; Soy products; Aglycone; Daidzein; Genestein. 